\title{
Surfaces
}

\section{REVOLUTIONS PER MINUTE OR THE PET SHOP BOYS FOREVER}

\section{Ian Balfour}

Volume 1, 1991

URI : https://id.erudit.org/iderudit/1065250ar

DOI : https://doi.org/10.7202/1065250ar

Aller au sommaire du numéro

Éditeur(s)

Les Presses de l’Université de Montréal

ISSN

1188-2492 (imprimé)

1200-5320 (numérique)

Découvrir la revue

Citer cet article

Balfour, I. (1991). REVOLUTIONS PER MINUTE OR THE PET SHOP BOYS

FOREVER. Surfaces, 1. https://doi.org/10.7202/1065250ar
Résumé de l'article

Le rapport entre la révolution et le temps historique, la politique de la musique pop. Comment le groupe britannique The Pet Shop Boys soumet la musique pop, la sexualité et la politique à une rhétorique de l'infini. 


\title{
REVOLUTIONS PER MINUTE OR
}

\section{THE PET SHOP BOYS FOREVER}

\author{
$\underline{\text { Ian Balfour }}$
}

\begin{abstract}
The relation of revolution to historical time, the politics of pop music. How the British group The Pet Shop Boys submits pop music, sexuality and politics to an infinitizing rhetoric.
\end{abstract}

\section{RÉSUMÉ}

Le rapport entre la révolution et le temps historique, la politique de la musique pop. Comment le groupe britannique The Pet Shop Boys soumet la musique pop, la sexualité et la politique à une rhétorique de l'infini.

The Pet Shop Boys as the whole of human culture? A simple mistake for aliens to make, as they arrive on earth and discover only the recordings of the premiere British post-disco band. Or at least such is the scenario for a rendition of the Pet Shop Boys' song "So Hard" as framed by the prankster pop duo known as KLF, a name fabled to stand for Kopyright Liberation Front. If not quite the whole of human culture, are the Pet Shop Boys nonetheless something more than one cultural unit among others? If they were not something of the sort already, the very act of singling them out for 
analysis turns them into an example, an example of something larger and more comprehensive than the thing itself. But no sooner has one said this than one has to acknowledge some of the ways in which the Pet Shop Boys are counter-exemplary, so set apart from their mainstream contemporaries that the Pet Shop Boys often appear to be like nothing else. Where else in the diction of pop songs does one come across words like "trepidation," "litany," and "humdrum"? Where else would one come across a pop song based on the memoirs of Shostakovitch, wondering what to do about art in the aftermath of communism? What other group would be equally at home working with Dusty Springfield and Derek Jarman? Yet even in their eccentricity, the Pet Shop Boys exemplify and have a good deal to tell us about the character of contemporary pop, especially, as we shall see, in matters of temporality.

The ideal Pet Shop Boys song lasts forever. By that I don't quite mean that this ideal song - if there were such a thing - would be monumentalized in some eternal canon of pop music, an analogue to Beethoven's Third Symphony or The Magic Flute. I mean rather that there is often something in the structure and the syntax of a Pet Shop Boys tune that suggests the song could - and probably should - "go on and on forever." This last phrase "go on and on forever" - turns up in the Pet Shop Boys version of a Sterling Void song titled "It's Allright", and it's only one of countless insances of a pervasive preoccupation with infinity that bears some scrutiny.

The work of the Pet Shop Boys, I would suggest, participates in a more of less conscious "infinitizing" of the pop

\section{/pp 5-6/}

song that has taken a number of different forms since the mid-sixties. Early rock and pop were dominated by the two and a half minute song, and its tyranny was so nearly absolute as to give any song lasting significantly longer than that something of the effect of going on forever - or what is just as important - of potentially going on forever. In contrast to rock and roll proper, each of the sub-genres of folk-rock, art-rock, and acid-rock provided vehicles for songs of considerable length, as long as and sometimes longer than the side of an album. These were impossible to hear on AM radio, and FM rock stations virtually had to be invented to accomodate the Grateful Dead's "Dark Star" or long Doors' songs like "The End" and "When the Music's Over": the titles themselves are telling. No doubt something like Iron Butterfly's "In-a-Gadda-da-Vida" would sound today as if it really does go on forever, even if, technically, it lasts only fourteen minutes. But something of the infinity of the pop song can come into play as soon as one crosses the sound barrier of two and a half minutes, there is no generic imperative that says the song has to stop anywhere in particular. But before getting carried too far away with this thesis, one should perhaps discriminate between the various modes of what I am somewhat 
hyperbolically calling the "infinitizing" of the pop song. And the Pet Shop Boys' music in this regard constitutes at once something specific and something exemplary.

Even the most minimal musical material can in principle be "infinitized" by simply programming in a permament repetition or series of variations, along the lines, say, of Eric Satie's experiment of the performance of a single, highly repetitive composition lasting 24 hours. What is intriguing about the Pet Shop Boys' corpus is the specific interplay of repetition and difference the repetition with a difference - that results in the sense that this music could go on forever.

The Pet Shop Boys, with the "voice" of Neil Tennant and the "noise" of Chris Lowe, are now one of the premiere pop bands, especially popular in clubs where "mixed" - which is also to say, re-mixed - music plays to dance audiences. In clubs, one hears not the /pp 6-7/

still conventional two-and-a-half minute songs of AM radio and the video industry, but extended disco or "house" songs, and reworkings of songs that repeat and treat material from originals. These "originals" may or may not exist, and in the case of the Pet Shop Boys, they increasingly do not. In this, the age of the "sample," it has been said that there is hardly an original bit of music in the Pet Shop Boys' work. There's a grain of truth to this, though often the quotations in their music are, so to speak, generic: they quote genres in addition to quoting, or even sampling riffs or melodies from other songs. The technical innovations offered especially by digital recording make the endless reworking of a song easier than ever before, and one sign of virtuosity in mixing is to distort the original in spectacular ways, often while still remaining within the now extended parameters of the original. Voices and instruments will be raised or lowered in pitch, sped up, slowed down, scratched into a kind of stutter, or synthesized so that one hears the ghost, not so much in the machine as of the machine. The pop music of our techno-culture is produced by the Zeit-ghost of the sequencer and the drum machine. It is precisely this sort of technology that contributes to a certain "aura" of the infinite. We know that a Sex Pistols song or a high-energy John Zorn number could not go on forever, because it would be physically impossible. But the technical reproducibility foregrounded in the work of bands like Kraftwerk - with their cultivation of the robotic and the sheerly technological extending from the instruments to the body and the voice - or Psychic TV, with their rhetoric and performance of The Infinite Beat" - or KLF with their impish sampling pyrotechnics of dance music, thematizing infinity in a track like "3 A.M. Eternal" - operates in a very different register, with an utterly distinct sense of temporality. The music of the Pet Shop Boys, with its seemingly effortless and mechanical movements, suggests that it could, given the right programming, go on and on forever. 
There is indeed a certain specificity to the Pet Shop Boys love affair with the long song. Neil Tennant - himself a former rock journalist with Smash Hits admitted to being repelled in the 1970's /pp 7-8/

by Led Zeppelin fans, by their fervour, to say nothing of their appearance (all in "beards and greatcoats") and he became, in protest, a fan of the Incredible String Band, whose twenty-minute compositions remain an ideal the Pet Shop Boys strive for. But the Pet Shop Boys effect something of a revolution per minute with their songs of six, nine, and eleven minutes long, for even in these circumscribed formats, they too raise the spectre of a song that need not end.

The ghost of pop music assumes a more haunting and a more questionable shape - in the neutral sense of the term - in the phenomenon of the "cover," the reworking of a song by a different group usually from a different era of rock or pop, though the temporal gap between original and cover is now getting shorter all the time. Here repetition is not just one structural feature among others, but the very principle of the music. A good many rock covers are simply easy vehicles for making money, a calculated cashing in on the familiarity of a lyric and a melody line. But the more substantial covers tell us something about - and even reflect upon - the history of their genres.

One such production has come to be something of a signature song for the Pet Shop Boys: namely, their cover of Elvis Presley's "Always on my Mind," which had in the not so distant past also been covered by Willie Nelson. Much like the Fine Young Cannibals' "Suspicious Minds" - the respective videos have a number of affinities - "Always On My Mind" is something of an homage to the Elvis original, an acknowledgement and partial payment of a debt. Certainly the video of "Always On My Mind," featuring a few frames of Neil Tennant in a tight gold lamé suit, seems to suggest to the Pet Shop Boys can't really fill the shoes, blue suede or otherwise, of the larger-than-life, indeed of the immortal Elvis: the gaunt body of Neil Tennant sans sideburns simply doesn't measure up. But in the hands of the Pet Shop Boys "Always on My Mind" becomes something more than and different from an homage, an example of what one can even call, after Derrida, a "reinscription." Not only is the original ballad thoroughly /pp 8-9/

reconfigured by being set to a disco beat, there is a turning point in the process of rewriting when the cover ceases to be merely that, and is, so to speak, discovered. Or perhaps it uncovers an allegorical layer of the "original," for halfway a number of versions of the song, the refrain "you were always on my mind" is suddenly transposed into: "you were always in my house". So what was once the plaintive lament of a lover who recognized too late that he should have been more expressive of his feelings, turns into 
the reproach of someone unduly put upon in a relationship. Regret turns to resentment: the once gentle omnipresence of the loved one is recast as the oppressive ubiquity of an unwanted guest. In this "house" music, the Presley song itself is an invited guest, hosted by the parasite cover. But if the Pet Shop Boys' version is still a kind of homage, it's a distinctly Nietzschean one, negating and exceeding the thing that gave it life in the first place. Perhaps it's trying to be a simpler sort of homage, though I think even its authors recognize the sort of twist - if I can call it that - they perform in giving us an Elvis other than that of tabloid culture. But their Elvis is immortal too, after a fashion, momentarily given mouth-to-mouth resuscitation, so that his song can live an after-life. Yet the song goes well beyond the examples of Elvis and Willie Nelson. Its rewritten refrain - "you were always in my house" baldly states the programme of "house" music generally: any phrase or riff in the database of music history can be accessed - randomly and not so randomly - - and taken up into a mix that is nothing if not citational. House music is always saying to the discography of its prehistory: "you were always already in my house."

The Pet Shop Boys 1991 version of U2's "Where The Streets Have No Name" presents a rather different instance, much less an homage than "Always On My Mind" could ever be. U2 represent the archetypal rock group, opposed implicitly to all that disco or pop stand for, and the polemical irony of the Pet Shop Boys' doing a song by U2 was not lost on the Irish group with workingclass roots, known for their aura of authenticity. Their guitarist, The Edge, is said to have responded to the news that the Pet Shop Boys would be doing the song by asking "What have we

/pp 9-10/

done to deserve this?", echoing the title of the Pet Shop Boys' famous collaboration with Dusty Springfield. From the start, the relationship could almost only be considered as the Pet Shop Boys versus U2. Were it not for its melody, U2's passionate plaint of the "sensitive man" set for voice and guitar would scarcely be recognizable, especially in its arch-disco versions - two of seven variations on the same song - where synthesizers and strings have wholly displaced the guitars and drums of the original. The transformation in the arrangement has a corrosive effect on the lyrics, underlining the often pretentious existentialism of U2, even though the words remain the same. Not content to simply rework the song of their contemporary arch-rivals, the Pet Shop Boys segue from "Where the Streets Have No Name" to "Can't Take My Eyes Off of You," even linking the syntax of the two sets of lyrics so that they form a single unlikely amalgam. That both songs - and the voices of Frankee Valee and Bono, the former falsetto and the latter booming and "manly" - are filtered through the tremulous but confident voice of Neil Tennant also has the effect of deflating U2's anthem. And just in case the first movement of the song risked being a conventional cover, the abrupt switch from U2 to the Four Seasons, in its audio montage of groups anathema to each other, defamiliarizes each in a way that marks rather than 
collapses the distance between original and cover. That the Pet Shop Boys' cover is decidedly not an homage is one index of a disposition in their work not to wallow in the past, something they see a good deal of in rock culture. Whereas much contemporary rock is haunted in a disabling way by an increasingly canonical tradition - a history that weighs on it like some mountain - the Pet Shop Boys' mode of citation and cover is, so to speak, future-oriented, precisely because of their retroactive transformation of the original. Whether a cover is past- or future-oriented is not entirely in the control of the musicians or composers, but one can show, as later will be the case with "Being Boring," that even when the past is addressed most explicitly in the Pet Shop Boys, not only is the reflection on that past oriented toward an uncertain future, the past itself suddenly looms up as if its status too remains to be determined.

/pp 10-11/

To this point we have encountered two models of time, not necessarily compatible with each other, one of a certain temporal infinity - in the potentially unending techno-mix - and another of repetition, in the guise of the "cover" song. We can pursue the model of infinity in yet another register, for infinity is not just not just a structural matter of the long song: there is, as well, a curious syntactic infinity - a grammar of infinity - that pervades the language of the Pet Shop Boys.

The key phrase common to both refrains in "Always on my Mind" is "you were always..." and these words recur in just that form, as a non-sentence, incomplete, suspended at the word "always ...". This structure is a virtual hallmark of the rhetoric of the Pet Shop Boys: a half-dozen songs feature refrains of truncated sentences that never end. The possibilities for completion are to some extent marked out by the lyrics: for upon hearing the phrase "you were always ...", we are free to fill in "on my mind" or "in my house," but perhaps something else as well. That is to say, there is a syntactic open-endedness at work, co-existing with the structural infinity of the extended and extendable mix. This syntactic infinity is accomplished primarily through ellipsis, the simple omission of terms. One can always, again, fill in the ellipsis. But there remains a divide between the elliptical and the complete: they are not simply two different ways of saying the same thing.

The conjunction of the elliptical and the infinite dominates one remarkable track called "Love Comes Quickly," where this time the grammar of infinity is thematized in erotic terms. At the simplest level, the song describes the unpredictability of falling in love. "Just when you least expect it," the Pet Shop Boys tell us, "just what you least expect". To fall in love suggests a finite rather than infinite experience, a certain impact that will end or be 
transformed into something else. And its finite character seems assured from the start, because if loves comes quickly, then one is either is in love or not. But the syntax of the song implies that the fall itself is not so quick: it may come quickly, but the fall itself goes on and on. "You can't stop falling," chants the refrain, "you can't stop falling." In love, of /pp 11-12/

course, we might be tempted to fill in, not being able quite to tolerate ellipsis. But that's not exactly what the lyrics say: the force of having the complement left out infinitizes the falling: it just goes on and on In its infinity, it's a free fall, but in another sense, it's not free at all, for no one has any choice in the matter. "Sooner or later," we are assured, "this happens to everyone." So in the erotic world of the Pet Shop Boys - and we'll see in a moment how the erotic too is preminently a locus of infinity - sooner or later everyone falls in love quickly and can't stop falling. This is not simply a "fallen" world, as in other Pet Shop Boys songs redolent with something like Catholic guilt: "It's a Sin," for example, with its refrain of "Father, forgive me". It is, rather, a falling world, a world of falling with no end in sight.

In the universe of the Pet Shop Boys, the erotic is frequently bound up with dance and with music generally, as in the song called "Heart". It begins with the staccato phrase: "beat / a heart beat" and it's difficult to tell one from the other, not least because the thing that love and dance music have in common is that they both make the heart beat a little faster. True to the convention of the pop love song, romance is the sphere where the illusion of things going on and on is created.

For The Pet Shop Boys the erotic is linked to dance music because of their similar capacities for the manufacturing of such illusions. The refrain of "Hit Music" assures the auditor: "When you dance with me, we dance forever - all night long to the latest song." Precisely at the moment that the song underscores the ephemerality of pop commodity culture - invoked in the title and in the idea of "the latest" - it also revels in the sense of dancing going on forever. It is this paradox - the sense of time passing together with the sense of time standing still - - that structures the temporality of the Pet Shop Boys.

This state of affairs marks the song bearing the oxymoronic title "Tonight is Forever". On the one hand, the song simply celebrates a sense of escape from the quotidian and the banal - a 
prominent theme in the Pet Shop Boys, with their songs entitled "Shopping" and "Rent" [the deadpan refrain of "Rent" goes "I love you, you pay my rent"] - a sense of escape such that time appears not to be passing by. The lyrics chant: "It will be like this forever, if we fall in love" and the track sounds at first, with its luxurious strings and dreamy melody, like an archromantic love song. But that line is preceded by the phrase "I never have enough." Which is to say that falling in love may well be identical to never having enough, to forever having enough, underlining a further, doubleedged infinity of the erotic, in which desire never coincides with its object. That this gap is a temporal one is suggested in the Pet Shop Boys' "Paninaro," in which eternal verities like "money," "religion" and "death" are juxtaposed with the fleeting changes that we know as fashion: "Armani ... A A - Armani," stutter the sysnethesized voices. So the world of the erotic is fraught with the same soort of temporal complexity we hav glimpsed in other registers of the Pet Shop Boys' work. KLF's question: "What Time Is Love?" doesn't permit a simple answer.

If speaking of the shift from the two and a half minute song to the long song as something of a "revolution" was primarily a bad pun on the revolutions per minute of the disks themselves, then things may only get worse when we take up another realm where infinity surfaces as a theme in the Pet Shop Boys: namely, political revolution. The Pet Shop Boys would hardly seem to take a prominent place in any list of politicized British bands of the 80's, like The Clash, The Housemartins, or Gang of Four: the Pet Shop Boys, after all, make pop music, not "revolution rock," as The Clash call it. Yet a curious and not so subterranean insistence on revolution proper riddles their work from beginning to end.

Take the song, "Left To My Own Devices," for example, whose refrain goes like this:

I could leave you, say good-bye

And I could love you, if I try

And I could

/pp 13-14/

And left to my own devices 
I probably would

Here again we glimpse something of the ellipsis of infinity. Following "I probably would ..." we could well fill in "love you" but, strictly speaking, the phrase remains ambiguous, even undecidable, since the two possibilities loving and leaving - seem mutually exclusive. And the semi-certainity of the word probably is replaced in one version of the song's final line, such that it reads "I possibly would," thus qualifying the declaration even more. In this song, a virtual credo for the Pet Shop Boys, the harmless word "left" takes on an unexpected significance when the speaker, who has just described how he lives in a world of his own at the back of the garden, proceeds to tells us:

But at the back of my head

I heard of distant feet

Che Guevara and Debussy to a disco beat.

This last line emerges as something of a motto for the Pet Shop Boys, whose vision of the revolution comes with strings attached: here the orchestral strains of Debussy incongruously tied to the figure of the archetypal guerrilla leader. These verses - replete with allusions to Andrew Marvell, comrade of the most radical poet in English history - are soon followed by a line, the likes of which has rarely been heard by dance club clientele: namely "In a secret life, I was a Roundhead general". What can a reference to the 17th-century English Civil War be doing in a disco love song? If before we saw that the beat of a dance tune was aligned with the heartbeat of love or something like it, love and revolution emerge here as allegorical versions of each other, in their radical open-endedness, their sheer unpredictability. And this too has has something to do with the long song as understood by the Pet Shop Boys, with their elaborated ideal of the song whose end we may never know.

To pursue the links between the rhetoric of revolution in its political and its musical modes, I want to return now to the song

/pp 14-15/

invoked at the outset, the Pet Shop Boys rendition of "It's Allright," as another and distinct instance of their preoccupation with infinities. The song exists in two versions, the first on the album "Introspective," where it lasts 
more than five minutes and the second on a twelve-inch single where it lasts approximately eight. The structure of the extended version is radically different, for the intro of the song - up to the point where it sounds like the body of the original - lasts over five minutes. That is to say, the intro is longer than the body of the song proper. It plays with the listener's sense of what the preamble of a song is supposed to be - much like New Order's "Thieves Like Us," - such that the normal relation of intro to song is undone. And as the song performs this rewriting - with its intro going on and on - - it underscores the infinity of nothing other than music itself.

The initial refrain of the song - "I can hear it on a timeless wavelength" - first sounds the theme of infinity, soon underlined by the the phrase: "and it goes on and on and on and on and on." Everyone has heard people go on and on, and it's not very pleasant, but for the Pet Shop Boys the going on and on of music is ascribed a thoroughly utopian power. Music is the thing that will outlast everything else and, in the world of the Pet Shop Boys, it's a good thing too.

The remake of "It's Allright" participates in a different kind of infinitizing as well - or at least a generalizing of a political thematics that marked the original version of the song.

The original first verse went as follows:

Dictation enforced in Afghanistan

Revolution in South Africa taking a stand

People in Eurasia on the brink of oppression ...

This bleak and hardly profound political comment - pop music is generally the wrong place to look for trenchant social criticism - is followed by the simple wish that things will be all

/pp 15-16/

right. And here the logic takes a bizarre turn, for the Pet Shop Boys proclaim that it will be all right because the music lasts forever. Historical predicaments come and go, as do even nations: music, we're told, "is our 
life's foundation and shall succeed all the nations that come". It almost sounds as if we're reading Plato on the music of the spheres. And yet, in another register, the music of the Pet Shop Boys is music of the public sphere, and has no illusions about its historical character, its embeddeness in that formation we optimistically call "late" capitalism. But listening to what happens to the opening verses of "It's Allright" when it is reworked, we find a momentary effacement of what we usually think of as history. The rewritten version goes like this:

Forests falling at a desparate pace,

The earth is dying and desert taking its place,

People under pressure on the brink of starvation.

I hope it's going to be all right,

Cuz the music plays forever.

Gone are the specific references to Afghanistan and South Africa and the less specific one to Eurasia, and in their place we are left with forests, trees, and generic people.

On the other hand, in a song like "West End Girls," what starts out as the description of encounters between upper and middle class girls of London's West End with lower class boys of the East End, gets translated into a global, but still palpably historical configuration:

Got no future, got no past,

Here today, and built to last,

In every city, in every nation

From Lake Geneva to the Finland Station

I take this somewhat opaque allusion to mean from east to west in the global sense, from Lake Geneva - home of Rousseau, the "brains" behind the French Revolution - to the Finland Station, 
the site in Moscow to which Lenin, in April of 1917, returned from his exile in Switzerland and the West. The understated but remarkable appeal to these revolutionary moments links up with all the future-oriented mechanisms we have been associating with the concept and the performance of infinity in the Pet Shop Boys, for revolution is precisely what renders the future absolutely precarious, to say nothing of unknowable. "You wake up in the morning, and there's still no guarantee," the Pet Shop Boys tell us in another song.

But it is not only the future that is open-ended. In "October Symphony," the recent 1990 song based on Shoshtakovitch's memoirs, what is at stake in the present, the new revolutionary moment of Perstroika and Glasnost, is the meaning of the past Russian Revolution, and that meaning is, it turns out, by no means fixed. The song stages Shostakovitch's struggle over how to rethink his October Symphony, whether to change the dedication, as Tennant and Lowe say, "from revolution to revelation". For now the Russian people - a chorus of whose voices are cited in the opening bars of the song are being told that they "were never even saved". One used to be able to count on the peaceful "revolution" of the seasons, to count on October coming around again, with its meaning not at all all in doubt. But now: "So much confusion," the Pet Shop Boys remark in Shostakovitch's voice, "when autumn comes around." In the process of history's regularization, it was as if the rhythm of nature had become with the rhythm of history itself. But it is exactly in the moment of revolution that history emerges as most "historical," when the contingency of events and the unpredictability of the future become most apparent, when all of a sudden history the possibility of things being radically otherwise.

The rhetoric of revolution in the Pet Shop Boys may seem at odds with pop music and its all-pervasive commercialism, as opposed to rock proper, which still often presents itself as anti-commercial, even when flying in the face of economic facts. In an interview for New Musical Express - given in the house of William Hazlitt, the radical essayist who no doubt would have been the first

/pp 17-18/

rock critic, had there been such a thing - Neil Tennant commented on a certain historical irony now besetting the rock industry: "... the funny thing is that rock music has becomes the most safe and polite institution of all. Bono inducting the Who into the Rock and Roll Hall of Fame, all in their wing collars and bowties. Talk about bloody irony!" 
By contrast, the Pet Shop Boys corpus, with its appeals to Che Guevara, Lenin, and Roundhead generals, is pervaded by a certain romantic anticapitalism: it relentlessly exposes the ubiquity of commercial commodity relations that insinuate themselves, as William Godwin said of government generally, "into our most private transactions." We're "S-H-O-P-P-I-N-G, " the song of that name reiterates, even when it's clear that something more than literal shopping is entailed. This track, often received as a kind of jaded endorsement of sheer commercialism is, in fact, a pointed attack on the Thatcherite policy of privitization: "We heard it in the House of Commons / Everything's for sale," chant the Pet Shop Boys, as they put a political spin on what would otherwise be a commonplace about the banalities of everyday life in the material world.

In the end, the final sort of revolution I want to talk about could be called I'm not inventing the term - the sexual revolution. A columnist for Spin magazine writing in the New York Times has spoken of the Pet Shop Boys "science of ambiguity" - not least in terms of sexuality, claiming they could come off either straight or gay. The apparent facts of the Pet Shop Boys' sexual orientation have caused some difficulty for popular press coverage of the band, especially publications geared for a teen audience. One English photobook devoted to the Boys had to cover as follows for the absence of knowledge on the subject of Neil and Chris' love life:

The Pet Shop Boys; two successful, talented, handsome, lads, who've put their original stamp on the music of the decade. But what about their love lives? Neither of them are married but the music magazines and newspapers seem to be totally lacking in anything at all to do with girlfriends or the /pp 18-19/

sort of girls that they like - information that would be of great interest to their thousands of female fans! To correct this imbalance, we consulted our resident astrologer, Darcy De La Quinten, and asked him to construct an astrological love chart so that anyone interested (about 5 million of you) can see whether your star signs are compatible with those of Neil and Chris.

It's no accident that a number of the Pet Shop Boys' videos have met with some resistance at MTV because they departed from certain norms of video production. In the video for "Domino Dancing" - which features talk of wanting "a love of a different kind" - two guys are fighting over a girl. But the camera soon becomes interested primarily in the two guys, who, at the end of video, are seen stripped to the waist, jostling with each other on a beach, to the point where, caught in each other's arms, they are pictured falling to the sand. The video cuts the scene of falling short and repeats it four times. They never reach the beach: they just can't stop falling.

Something in the camera's insistence on watching two half-naked men fall in 
each other's arms was a bit much for MTV, who apparently would cut off the ending of the song. MTV would not confirm this in telephone conversations, but they did have to deny that they did and do not play the video I want to address in bringing this analysis to a conclusion.

The most spectacular staging of a certain sexual revolution occurs in the latest video from the new album: the track entitled "Being Boring". The opening sequence of the video, shot by Bruce Webber, is thoroughly atypical in its focus on the male nude body: indeed it is unheard of in the imaginary of mainstream music video. It is, after all, in Madonna's words, "a hetero world" - a phrase coined not only in reference to MTV. And if, in the largely hetero world of MTV, the gaze is male (as Laura Mulvey has argued for the cinematic apparatus generally), then attention to a statuesque male nude cavorting with a dog, no less - cannot but be coded as homoerotic. Yet one senses the reductiveness of calling this video "gay" - and not just because it goes on to display any number of /pp 19-20/

relationships, a good many of them "hetero", some of them gay, some sheerly narcissistic and autoerotic, some seeming to resist any names of this order.

The exhuberance of this video is all the more striking when we become aware that it is an elegy for an AIDS victim, as signalled in the lines: "All the people I was kissing / Some are here and some are missing / In the nineteen nineties." Against all odds, this video text is an extraordinarily affirmative and exhilirating elegy, at once contemporary and a flashback to a time when sex need not have been qualified as safe. Both the song and video have very complex structures of temporality, some sense of which can be glimpsed in the refrain of the lyrics:

We were never being boring,

We had too much to fight for ourselves.

We were never being boring

We dressed up in thoughts and thoughts make amends.

We were never holding back, worried that

Time would come to an end.

We were always hoping that, looking back, 
You could always rely on a friend.

The almost vertiginous movement backward, forward, and back again in time is supplemented by its eccentric grammar ("We were never being boring,"- a phrase that yokes together finitude and infinity) and by visual images like that of a teenage boy at a resolutely 90's party flashing his jacket open to reveal a Hendrix teeshirt. Moreover, the free-form dancing proper to a party stands in marked contrast to the mainstream video choreography in the mode, say, of Janet Jackson or Paula Abdul. Its uninhibited character has virtually an anarchic effect, given the regimentation of the competing models.

The song begins by recalling a "cache of old photos" and "invitations to teenage parties," the motifs of which are both taken up into the ultracontemporary texture of the video, with its black

/pp 20-21/

and white footage recalling but not reduplicating the old photos, also no doubt in black and white. At once nostalgic and not nostalgic, the dizzying sequences of the video cite the past, even as the camera and the words know they could never coincide with that past.

But what could these scenes of abandon, this "revolutionary" moment have to do the structures of infinity we have been underlining in the work of the Pet Shop Boys? If we take the heterosexual relation as the dominant model and assign it, say, the number one, then the move beyond the heterosexual model opens up, at least momentarily, the sense of all the configurations beyond it, even if we know that, numerically, the relations are not exactly infinite: the list doesn't quite go on forever.

We have been stressing the infinity and unending character of the Pet Shop Boys work - in the structure of their songs, in the thematics concerns of love, music, and revolution, even in their very grammar - but the "Being Boring" video is virtually the only place in their unfinished corpus where one is really confronted with thinking of an end. Even in their recent song titled "The End of the World," the refrain undercuts precisely that notion: the chorus repeats "It's just a boy or a girl, it's not the end of the world." In "Being Boring, " it's a different story, with its invocation of all those who would be here, were it not for AIDS. We have to think of an end in absolute terms, but even here not perhaps of an absolute end. For to return to the 
terms of "It's AllRight," the music goes on and on forever - it has to go on on

- because in the logic of the Pet Shop Boys, silence equals death.

\section{York University}

Dept. of English

Winters C - North York, Ont, M3J 1 P3 - Canada

$/ \mathrm{p} 21 /$

Surface Page d'Acceuil/Home Page 